\title{
Imposto de importação e sua função extrafiscal ${ }^{1}$
}

\author{
Analice Ohashi da Trindade ${ }^{2}$ \\ Cristel Rodrigues Bared ${ }^{3}$ \\ Patricia Luz da Silva ${ }^{4}$
}

\begin{abstract}
Resumo
0 presente artigo científico apresenta a característica extrafiscal do imposto de importação, desnudando sua importância no desenvolvimento social e econômico do Estado. Entretanto, aponta os perigos de sua aplicabilidade, em razão do poder conferido ao executivo para flexibilização das alíquotas impostas, ainda que presente a motivação imprescindível para regular eficácia do ato administrativo. Demonstra ainda, mesmo sem aprofundar-se no mérito, os prejuízos jurídicos deixados à livre interpretação das normas tributárias sem compreendê-las na sua construção, finalidade e eficiência.
\end{abstract}

Palavras-Chave: Imposto de importação; Extrafiscalidade; Flexibilidade de alíquota; Benefícios e prejuízos.

\section{Introdução}

Também denominado vulgarmente como tarifa aduaneira, direitos de importação, tarifa das alfândegas ou direitos aduaneiros, o imposto de importação é um tributo de competência da União, e assim se justifica porque, em se tratando de um imposto com implicações no relacionamento do país com o exterior, seu trato deve caber na verdade à União, responsável por este relacionamento, que deve ser uniforme no âmbito internacional, e não se deve projetar a personalidade jurídica dos Estados-membros, mas da Federação como um todo.

Este imposto vem ganhando importância no cenário internacional, pois constitui uma arma que os paises utilizam em suas negociações internacionais, e, em virtude da sua importância política econômica é objeto de inúmeros tratados, visando à cooperação internacional e a necessidade de integração dos países face à globalização, através do livre trânsito de bens, serviços e fatores produtivos entre paises signatários.

\footnotetext{
${ }^{1}$ Trabalho apresentado como requisito parcial de conclusão da disciplina de Direito Tributário do curso de Graduação em Direito da Universidade Estadual de Londrina.

${ }^{2}$ Graduanda do Curso de Direito pela Universidade Estadual de Londrina.

${ }^{3}$ Graduanda do Curso de Direito pela Universidade Estadual de Londrina.

${ }^{4}$ Graduanda do Curso de Direito pela Universidade Estadual de Londrina.
} 
Este contexto justifica que o referido tributo seja objeto de estudos mais aprofundados, e é exatamente este o escopo do presente trabalho, que, primeiramente discorre sobre a regra matriz de incidência fiscal do imposto de importação, passando pelo estudo da hipótese tributária e seus critérios material, espacial e temporal, e posteriormente a relação jurídica tributária, identificando o sujeito passivo, sujeito ativo, base de cálculo e alíquotas.

0 último tópico do presente estudo assume um caráter de ordem prática, com o escopo de finalizar a pesquisa chegando a conclusões a respeito do uso adequado da extrafiscalidade, função inerente aos impostos ligados ao comércio exterior.

\section{Regra matriz de incidência tributária - imposto de importação}

Hipótese tributária

Do critério material

A hipótese composta pelo critério material traz em seu bojo o verbo importar, o qual significa trazer para dentro do território importador. Nem sempre, segundo Hilú Neto (2003, p. 65-67), a conduta importar será passível de subsunção na Hipótese Tributária do Imposto de Importação, afinal o importar previsto pelo legislador remonta à finalidade da conduta tributável, devendo-se para tanto observar a finalidade de uso ou consumo, ou seja, incorporar-se à economia nacional. Afinal, a mercadoria pode estar apenas de passagem pelo território aduaneiro. Essa interpretação sobre a finalidade da importação demonstra-se necessária, posta a coerência do sistema jurídico tributário que norteia o próprio tributo.

o seu complemento, mercadoria estrangeira, deve ser observado com particularidade em especial o termo mercadoria, haja vista que a Constituição Federal ao auferir competência à União para instituição do referido tributo, o fez utilizando o termo produto. A observância é valida, posto que produto significa de forma geral: bem corpóreo e móvel, enquanto que mercadoria além de ser bem corpóreo e móvel, destina-se ao comércio. Diante disso, para fins de imposto de importação, produtos e mercadorias são palavras sinônimas e como tais, devem ser entendidas, sob pena de extrapolar a competência tributária. Afinal, retomando a interpretação coerente do sistema jurídico 
tributário, pode-se deflagrar a abrangência do referido imposto aos bens importados para 0 uso ou para consumo, logo, sem destinação à mercancia (HILÚ NETO, 2003, p. 78-81).

A qualidade de estrangeira implica em não ser nacional, ou seja, oriunda de território não abrangido pelo nacional. A propósito, mercadorias nacionais que deixam o território nacional passam a ser estrangeiras, ou desnacionalizadas, conforme documentação que registra o pagamento dos competentes tributos e regulariza tal saída e desnacionalização (HILÚ NETO, 2003, p. 84-87). Ousa-se inclusive inserir na qualidade de estrangeira, as mercadorias que entram no território nacional a partir da zona franca de Manaus. Essas mercadorias são importadas, porém não são submetidas aos tributos que as tornam nacionalizadas, vez que não completam a regra matriz no que tange ao critério espacial, logo, quando importadas por importador em outro ponto do território nacional assim entendido por aduaneiro, deverão ser submetidas à tributação sobre importação, haja vista preencher o critério material da hipótese, bem como o espacial.

\section{Do critério espacial}

O critério espacial que compõe a hipótese tributária do imposto de importação deve ser compreendido em consonância com dois sentidos de espaço:

Lugar no fato - intervalo territorial onde ocorre o evento tributável, o próprio critério espacial da regra matriz (CARVALHO apud HILÚ NETO, 2003, p. 136);

Lugar do fato - intervalo territorial onde é expedida a norma concreta individual, o lançamento (CARVALHO apud HILÚ NETO, 2003, p. 136).

Isso porque, o que vislumbra no critério espacial da hipótese tributária do imposto de importação é o lugar no fato, ou seja, território nacional, assim, o ponto da linha de fronteira cruzado pelo produto ao ingressar no território nacional.

Deve-se, entretanto, compreender que o território nacional, inserto na legislação tributária, equivale a território aduaneiro, o qual compreende todo o território nacional, no qual há alcance das normas jurídicas tributárias reguladoras das atividades de importação e exportação. Assim, excluída está a Zona Franca de Manaus, haja vista que Zona Franca é a área de um país considerada fora de seu território aduaneiro (HILÚ NETO, 2003, p. 137-142).

Contudo, território aduaneiro não se confunde com jurisdição aduaneira, posto que esta é o intervalo espacial no qual a autoridade competente tem poder de exercer 
plenamente a sua competência, em especial para controlar todos os aspectos das operações de importação e de exportação, tanto as tributações quanto as penalidades cabíveis em caso de infração (HILÚ NETO, 2003, p. 141-142).

Já os portos, aeroportos e pontos de fronteira alfandegários compõem o lugar do fato, pois são intervalos territoriais especialmente dotados de infra-estrutura para efetivar as atividades administrativas inclusas no conceito de jurisdição aduaneira (HILÚ NETO, 2003, p. 139).

Diante do exposto, o critério espacial do imposto de importação é o território aduaneiro, que engloba todo o território nacional, excluída a Zona Franca de M anaus.

\section{Do critério temporal}

O critério temporal da hipótese de incidência tributária do imposto de importação deverá ser observado em dois aspectos, haja vista sua imprescindível fixação para que sejam aplicadas as normas vigentes no momento exato da ocorrência do evento tributável.

Tempo no fato - momento em que ocorre o evento tributável, o próprio critério temporal da regra matriz (CARVALHO apud HULÚ NETO, 2003, p. 116);

Tempo do fato - momento de produção da norma concreta individual (CARVALHO apud HULÚ NETO, 2003, p. 116).

O tempo no fato é o momento em que os produtos cruzam a linha demarcatória do território aduaneiro, momento em que ocorre a entrada de fato, enquanto que o momento do fato é aquele em que ocorre o despacho aduaneiro, ou seja, a regularização da entrada da mercadoria - o lançamento, a entrada regular. 0 art. 23 do DL 37/66 prescreve que "quando se tratar de mercadoria despachada para consumo, considera-se ocorrido o fato gerador na data do registro, na repartição aduaneira, da declaração a que se refere 0 art. $44 "$.

A intenção de estabelecer o critério temporal, assim vislumbrada no art. 23, desponta em erro gritante por parte do legislador, afinal a momento da declaração de importação, tampouco é o tempo do fato, haja vista ser um dever instrumental preparatório da documentação de um evento futuro (LACOMBE apud HILÚ NETO, 2003, p. 125). É um momento anterior ao evento que poderá subsumir-se à hipótese de incidência. A propósito, fato gerador depende da ocorrência coordenada dos critérios que compõem a hipótese de 
incidência tributária, não se limitando a um só deles, afinal, a não identificação de um dos três critérios, fada a dinâmica descrita na hipótese ao comprometimento.

Ademais, flagrante confluência com o art. 1 으 do mesmo Decreto Lei, bem como com 0 art. 19 do CTN, os quais enfatizam o fato gerador do referido imposto, quando da entrada em território nacional.

Porém, este não foi o entendimento atribuído pelo STF em acórdão proferido em 06 de abril de 2001, através do qual entendem que o tempo do fato, ou seja, o despacho aduaneiro revelado, conforme entendimento amparado pelo art. 23 do DL 37/66, é o critério temporal, que compõe a hipótese de incidência do imposto de importação.

Porém, ao longo do estudo acadêmico, optou-se pelo tempo no fato, ou seja, o momento em que a mercadoria estrangeira importada entra - transpõe a linha demarcatória do território aduaneiro.

Assim, critério temporal é o momento da transposição da linha demarcatória do território aduaneiro.

Quando se tornar impossível de se verificar o momento supra, utiliza-se o momento de exteriorização do ato de vontade na incorporação das mercadorias à economia nacional nos casos de apreensão ou produtos abandonados.

Relação jurídico tributária

A relação jurídica tributária do imposto de importação, atendendo a regra matriz de incidência fiscal, traz os seguintes critérios: pessoal e quantitativo. No critério pessoal têm-se os sujeitos que atuam na relação jurídica referida, seja na qualidade de ativo ou passivo. E no critério quantitativo a base de cálculo e a alíquota. Aspectos que passamos a analisar.

Sujeito ativo

O sujeito ativo da obrigação é a pessoa jurídica de direito público, titular da competência para exigir o seu cumprimento (art.119, CTN). Na relação jurídica do imposto de importação o sujeito ativo é a União, nos termos do art. 153, I, CF e do art. 19 do CTN.

A União é o sujeito ativo, enquanto exerce todos os atributos que the são constitucionalmente conferidos em relação à matéria de importação, observado 0 critério 
material da hipótese tributária. Quando preenchidos os elementos componentes dos critérios material, temporal e espacial da hipótese tributária, a relação jurídica tributária estará deflagrada e a União estará legitimada para proceder a arrecadação do imposto de importação.

\section{Sujeito passivo}

O sujeito passivo da relação jurídica tributária no imposto de importação consiste na pessoa, física ou jurídica, que pratica o critério material da hipótese tributária diretamente ou outro determinado pela lei. 0 Código Tributário Nacional delimita a figura do contribuinte como o importador (ou quem a lei a ele equiparar) ou o arrematante de produtos apreendidos ou abandonados.

Em regra, o sujeito passivo do imposto de importação é o importador, pessoa que provoca a entrada de mercadoria estrangeira ou desnacionalizada no território brasileiro, assumindo a posição de contribuinte. Todavia, a lei equipara as figuras do arrematante de produtos estrangeiros apreendidos ou abandonados (em leilões alfandegários), do destinatário da remessa postal internacional indicado peli respectivo remetente e do adquirente de mercadoria entrepostada à figura daquele que deu causa à introdução da mercadoria no território nacional para fins tributários.

Importante destacar a figura dos seguintes responsáveis solidários: o transportador (quando transportar mercadoria procedente do exterior ou sob controle aduaneiro, inclusive em percurso interno), o depositário (assim considerada qualquer pessoa incumbida da custódia de mercadoria sob controle aduaneiro) e o adquirente ou cessionário de mercadoria beneficiada com isenção ou redução do imposto.

Com relação ao terceiro de boa-fé, a jurisprudência resguarda a boa-fé daquele que adquire $o$ bem estrangeiro mediante lícita transação com empresa importadora, que the fornece nota fiscal, não podendo este ser responsabilizado por irregularidade que antecedeu a aquisição. 


\section{Base de cálculo}

É o valor da transação da qual decorre a importação, entendido como tal o preço efetivamente pago ou a pagar dos produtos importados. De acordo com o CTN, quando a alíquota for específica a base de cálculo será a unidade de medida adotada pela lei para o caso. Quando a alíquota for ad valorem, a base de cálculo é o preço normal que o produto, ou seu similar, alcançaria, ao tempo da importação, em uma venda em condições de livre concorrência, para entrega no porto ou lugar de entrada do produto no país.

Integram o valor aduaneiro o custo de transporte da mercadoria importada até 0 porto ou aeroporto alfandegado de descarga ou o porto de fronteira alfandegado, os gastos relativos à carga, à descarga e ao manuseio e o custo do seguro da mercadoria durante estas operações.

O Acordo de Valoração Aduaneira (aprovado pelo Conselho do M ercado Comum do Mercosul - Dec. 1.765/95) fixa a base primeira para a valoração aduaneira como o "valor da transação", compreendendo o preço da mercadoria com ajustes (comissões, corretagens, custo de embalagens e recipientes, gastos com mão-de-obra e materiais, ferramentas e elementos semelhantes empregados na produção de mercadorias, materiais consumidos na produção, projetos de engenharia e de pesquisa, royalties etc.).

O objetivo principal dos ajustes a serem feitos ao preço das mercadorias, é a determinação de um valor para a base de cálculo do imposto que seja o mais próximo possível do efetivo valor da transação, evitando-se a utilização de bases de cálculo arbitrárias ou fictícias e protegendo a Fazenda.

\section{Alíquota}

É a relação entre o montante da riqueza tributável e o valor do imposto que está sendo cobrado em função dela. Para o imposto de importação ha duas espécies de alíquotas: a aliquota especifica e a ad valorem. A alíquota específica se expressa mediante a indicação de uma certa quantia fixa em dinheiro a ser multiplicada pelo número de unidades de medida de riqueza tributável, como peso, número e volume. Ex.: Imposto cobrado na importação de combustíveis - a alíquota poderá ser expressa por uma quantia em moeda, tantos reais, ou tantos centavos de real, por cada tonelada, ou por cada litro. 
A alíquota ad valorem (mais utilizada) se expressa mediante determinado percentual a ser aplicado à base de cálculo.

O Tratado de Assunção previu a instituição de uma Tarifa Externa Comum (TEC) sobre a base de cálculo, com o objetivo de incentivar a competitividade externa dos Estadospartes. Dispôs sobre as alíquotas (ad valorem) aplicáveis aos produtos importados e consolidou a integração dos países membros do Mercosul com a natureza de União Aduaneira. A TEC é organizada de acordo com critérios técnicos, em que os produtos são agrupados por natureza, espécie ou função segundo o grau de elaboração. As alíquotas estão dispostas em uma ordem lógica e, quanto à sua finalidade, pode ser proibitiva, protecionista e fiscal: a proibitiva visa a impedir a importação de produto estrangeiro; a protecionista permite a importação, mas atenta à proteção da indústria nacional, e, portanto, possui função regulatória; a fiscal - visa apenas à arrecadação.

Embora não o digam expressamente nem a Constituição nem o CTN, as alíquotas do Imposto de Importação devem variar conforme a essencialidade do produto, com o quê se estará pondo em prática o princípio da capacidade contributiva. Tais alíquotas são, de um modo geral, bastante elevadas exatamente para dificultar a entrada do produto no território nacional e dar, deste modo, melhores condições do produto nacional para competir no mercado (alíquotas elevadas representam um estímulo ao descaminho).

Sendo o Imposto de Importação um tributo com função predominantemente extra fiscal, foi ele colocado como uma das exceções ao princípio da anterioridade da lei ao exercício financeiro. Pode ser ele aumentado no curso do exercício financeiro. Também a ele não se aplica em toda a sua plenitude o princípio da legalidade, visto como suas alíquotas podem ser elevadas e reduzidas, dentro dos limites fixados em Lei, por ato do Poder Executivo.

\section{A extrafiscalidade e o imposto de importação}

O fundamento constitucional da tributação extrafiscal

A Constituição Federal de 1988 dispõe em seu art. 1ํㅡ, verbis: 
Art. 10 - A República Federativa do Brasil, formada pela união indissolúvel dos Estados e Municípios e do Distrito Federal, constitui-se em Estado Democrático de Direito e tem como fundamentos:

[...]

IV - os valores sociais do trabalho e da livre iniciativa.

Em seu art. 3ํ prevê os objetivos da República, verbis:

Art. 3o - Constituem objetivos fundamentais da República Federativa do Brasil:

[...]

II - garantir o desenvolvimento nacional

III - erradicar a pobreza e a marginalização e reduzir as desigualdades sociais e regionais

Da análise destes dispositivos depreende-se que o Estado Brasileiro "encontra-se comprometido com as idéias de justiça social e tem como um dos seus objetivos garantir o desenvolvimento nacional" (ARAÚJ0, 2006), bem como a livre iniciativa e os valores sociais do trabalho.

Os princípios deste Estado, apontados pela CF brasileira, são os pilares da construção de um Estado intervencionista por ela desenhado, com forte atuação nas relações sociais e econômicas.

O direito tributário está diretamente relacionado a estes princípios e ao modelo de Estado brasileiro, tanto no exercício da atividade fiscal, propriamente dita, quanto na função extrafiscal.

Isto ocorre porque no Estado desenhado pelo Constituição Federal de 1988, a arrecadação de tributos e a administração das finanças públicas além de assegurar o custeio das despesas do Estado Social, constituem um instrumento de regulamentação da economia, de desenvolvimento econômico e de justiça social.

Marcos de Freitas Gouveia (2006) assim define a extrafiscalidade:

A extrafiscalidade é um princípio ontológico da tributação e epistemológico do Direito Tributário, que justifica juridicamente a atividade tributante do Estado e a impele, com vistas à realização dos fins estatais e dos valores constitucionais, conforme as políticas públicas constitucionalmente estabelecidas, delimitada (a atividade estatal) pelos princípios que revelam as garantias fundamentais do contribuinte.

Nesse sentido, Ataliba e Gonçalves: 
Os incentivos fiscais manifestam-se, assim sob várias formas jurídicas, desde a forma imunitória até a de investimentos privilegiados, passando pelas isenções, alíquotas reduzidas, suspensão de impostos, manutenção de créditos, bonificações, créditos especiais e outros tantos mecanismos, cujo fim último é, sempre, o de impulsionar ou atrair, os particulares para a prática das atividades que o Estado elege como prioritárias, tornando, por assim dizer, os particulares em participantes e colaboradores da concretização das metas postas como desejáveis ao desenvolvimento econômico e social por meio da adoção do comportamento ao qual são condicionados (ATALIBA, 1991, p. 167).

\section{Classificação das normas extrafiscais}

As normas constitucionais extrafiscais podem ser classificas em três espécies. A primeira delas visa a realização de justiça social, "constituem um meio de intervir na vida social, de exercer uma pressão sobre os cidadãos, para organizar o conjunto da nação" (ARAÚjo, 2006). que podem ser exemplificadas através do principio da seletividade do IPI em função da essencialidade, e da não-incidência do ITR sobre o módulo rural.

A segunda espécie não é apontada pela maioria da doutrina, trata-se da extrafiscalidade política, que tem como escopo o fortalecimento do pacto federativo e também tem como objeto o fortalecimento das relações externas do Estado, principalmente com blocos econômicos (GOUVÊA, 2006).

Existem também as normas extrafiscais com 0 escopo de efetivação do desenvolvimento nacional.

Os impostos que incidem sobre o comércio exterior, são os que melhor evidenciam o objetivo de promover o desenvolvimento nacional como política tributária, pois, é notório que o controle de alíquotas sobre a importação constitui um importante instrumento de proteção da industria nacional, assim como o controlo sobre as alíquotas da exportação regulam a oferta de bens no mercado interno.

Uma política fiscal, por exemplo, que tem como objetivo incentivar 0 desenvolvimento nacional faz incidir uma carga tributária menor sobre os bens de capital e maior sobre propriedades ociosas e importações, com a finalidade de viabilizar o aumento da produção industrial. Neste caso, todos esses tributos têm uma função extrafiscal, ou seja, o objetivo dessa tributação é viabilizar a industrialização e não apenas arrecadar receitas para o financiamento do Estado (ARAÚJ0, 2003, grifo nosso) 


\title{
Extrafiscalidade no imposto de importação
}

O imposto de importação é um dos tributos mais antigos do mundo, e sua função primordial, desde os primórdios de sua criação, é extrafiscal.

No Brasil, sua importância enquanto instrumento de arrecadação de tributos é encoberta pela grande relevância que significativa na proteção do parque industrial nacional, daí o caráter essencialmente extrafiscal do imposto de importação.

Hugo de Brito Machado, brilhantemente discorre sobre a importância do imposto de importação no contexto atual.

\begin{abstract}
Se não existisse imposto de importação, a maioria dos produtos industrializados no Brasil não teria condições de competir no mercado com seus similares produzidos em países economicamente mais desenvolvidos, onde o custo industrial é reduzido graças aos processos de racionalização da produção e ao desenvolvimento tecnológico de um modo geral. Além disso, vários países subsidiam as exportações de produtos industrializados, de sorte que seus preços ficam consideravelmente reduzidos. Assim, o imposto funciona como valioso instrumento de política econômica (MACHADO, 2003, p. 272).
\end{abstract}

A função extrafiscal do imposto de importação vem sendo mitigada em virtude do processo de globalização que, cada vez mais, combate esta postura protecionista por parte dos Estados, defendendo a negociação internacional. Entretanto, a extrafiscalidade ainda é a principal função do imposto de importação, sendo inclusive utilizada como "moeda de troca" em negociações internacionais.

\section{Fundamento legal}

0 art. 21 do Código Tributário Nacional prevê a alteração das alíquotas do imposto de importação como instrumento de extrafiscalidade, in verbis:

Art. 21- 0 Poder Executivo pode, nas condições e nos limites estabelecidos em lei, alterar as alíquotas ou as bases de cálculo do imposto, a fim de ajusta-los aos objetivos da política cambial e do comércio exterior.

Quando editada esta norma estava sob a égide do da Emenda Constitucional no 7 de 1965, que previa a alteração pelo poder executivo, tanto da alíquota quanto da base de cálculo do imposto de importação. 
Entretanto, com a promulgação da Constituição Federal de 1988, o art. 21 do CTN não foi recepcionado integralmente, de acordo com o ${ }^{\S} 10$ do Art 153, a saber:

Art. 153 - Compete à União instituir impostos sobre:

I - importação de produtos extrangeiros

1o - É facultado ao Poder Executivo, atendidas as condições e os limites estabelecidos em lei, alterar as alíquotas dos impostos enumerados nos incisos I (importação de produtos extrangeiros), II, IV e V

Assim, foi imposta restrição à referida norma do CTN, limitando a possibilidade de alteração pelo poder executivo, somente à alíquota do imposto.

Cumpre salientar que esta possibilidade de alteração de alíquota pelo Poder Executivo só deve se concretizar em circunstâncias especiais que a justifiquem, e ainda assim, restritas aos limites estabelecidos em legislação ordinária. (M ACHADO, 2003, p. 299)

Como ato administrativo que são, as alterações de alíquotas pelo Poder Executivo, devem conter, necessariamente, a motivação bem fundamentada do uso da extrafiscalidade em cada caso, pois a motivação evita o desvio de finalidade do ato. (M ACHADO, 2003, p. 308)

Análise jurisprudencial

A margem facultada ao poder executivo pelo art. $1533^{\S} 10$ trata-se de uma exceção ao princípio da estrita legalidade, principio orientador do sistema tributário brasileiro. Neste feito o Poder Executivo deve fazer uso desta faculdade com parcimônia, sempre respeitando os as garantias e liberdades individuais e os demais preceitos constitucionais.

Todavia, a Fazenda Nacional, tem feito uso do pretexto de que o imposto de importação tem caráter extrafiscal para justificar de forma genérica a alteração das alíquotas do imposto, como se o este caráter "fosse uma liberação para cobrá-lo sem obediência aos preceitos da Constituição Federal." (MACHADO, 2003, p. 299)

Sobre este assunto, discorre Hugo de Brito Machado:

A extrafiscalidade, porém, não elide o principio da legalidade. Justifica, por certo, sua atenuação, simplesmente para permitir maior rapidez nas mudanças, sem 0 que o fim extrafiscal em muitos casos não seria alcançado. Não pode, entretanto, servir de pretexto para aumentos de alíquotas do imposto sem obediência ao 
princípio da legalidade mediante indicação genérica de circunstâncias que justificam o aumento, nem muito menos justifica a violação do principio da irretroatividade da lei (MACHADO, 2003, p.321).

Como exemplo do uso do argumento da extrafiscalidade pela Fazenda Nacional de forma indevida, a doutrina colaciona o Recurso Extraordinário 225.602, que colocou um ponto final à discussão sobre a aplicação dos Decretos 1.427 e 1.471, que majoraram a alíquota do imposto de importação de veículos que já estavam em território nacional aguardando o desembaraço aduaneiro. Decisão proferida em 1996 nos seguintes termos:

CONSTITUCIONAL. TRIBUTÁRIO. IM PORTAÇÃO: ALIQUOTAS: MAJORAÇÃO POR ATO DO EXECUTIVO. MOTIVAÇÃO. ATO. IMPOSTO DE IMPORTAÇÃO: FATO GERADOR. C.F., art. 11 II, 'a', e art. 153, 1 I.

I - Imposto de importação: alteração das alíquotas por ato do Executivo, atendidas as condi ções e os limites estabelecidos em lei: C.F. art. 153, § 10. A lei das condições e de limites é lei ordinária, dado que a lei complementar somente será exigida se a Constituição, expressamente, assim determinar. No ponto, a Constituição excepcionou a regra inscrita no art. 146, II.

II - A motivação do decreto que alterou as alíquotas encontra-se no procedimento administrativo de sua formação, mesmo porque os motivos do decreto não vêm nele próprio.

III - Fato gerador do imposto de importação: a entrada do produto estrangeiro no território nacional (CTN, art. 19). Compatibilidade do art. 23 do D.L. 37/66 com 0 art. 19 do CTN. Súmula 4 do antigo T.F.R.

IV - 0 que a Constituição exige, no art. 150, III, 'a', é que a lei que institua ou que majore tributos seja anterior ao fato gerador. No caso, o decreto que alterou as alíquotas é anterior ao fato gerador do imposto de importação.

V - R.E. conhecido e provido.

\section{Conclusão}

O Imposto de Importação, bem como o Imposto de Exportação, são impostos utilizados como instrumentos de política econômica, e têm como principal característica a extrafiscalidade, uma vez que são muito mais importantes como instrumentos de proteção industrial do que como meros instrumentos de arrecadação de recursos financeiros para o tesouro público.

Tem fundamental importância na proteção industrial nacional, pois o Imposto de Importação garante que produtos industrializados brasileiros tenham condições de competirem no mercado com seus similares produzidos em países economicamente mais desenvolvidos onde o custo industrial é reduzido graças aos processos de racionalização da 
produção e/ou, ao desenvolvimento tecnológico e/ou, aos subsídios garantidos à exportação de produtos industrializados.

O Imposto de Importação como instrumento de política econômica dever ser utilizado com cautela, ele deve ser reduzido ou excluído como instrumento para evitar a dominação dos mercados e o aumento arbitrário dos lucros. 0 uso inadequado do Imposto de Importação também pode ser um fator de atraso no desenvolvimento industrial, à medida que uma superproteção pode desestimular a modernização das empresas, sem concorrência, o produto nacional pode eventualmente abusar do mercado aumentando seus os preços.

Todos os argumento elencados tem grande relevância, entretanto, o uso da extrafiscalidade deve observar, sobretudo, o princípio da legalidade, da irretroatividade e os demais preceitos constitucionais, sob pena de agressão ao Estado Democrático de Direito.

\section{Referências}

ARAÚJO, Cláudia Rezende Machado de. Extrafiscalidade. Disponível em:

বhttp://www.senado.gov.br/web/cegraf/rel/Pdf/pde_133-29>. Acesso em: 27 nov. 2006.

ATALIBA, Geraldo; GONÇALVES, José Arthur. Crédito-prêmio de IPI : direito adquirido; recebimento em dinheiro. Revista de Direito Tributário, v. 15, n. 55, p. 162-179, jan./mar., 1991.

CARRAZZA, Roque Antonio. Curso de direito constitucional tributário. 20. ed. São Paulo: Malheiros, 2004.

GOUVÊA, M arcus de Freitas. A extrafiscalidade no direito tributário. Belo Horizonte: Del Rey, 2006.

HILÚ NETO, Miguel. Imposto sobre importações e imposto sobre exportações. São Paulo: Quartier Latin, 2003.

. A extrafiscalidade no Direito Tributário e suas Classificações. Disponível em: ব̀ttp://jus2.uol.com.br/doutrina/texto.asp?id=9151>. Acesso em: 27 nov. 2006.

M ACHADO, Hugo de Brito. Comentários ao Código Tributário Nacional. São Paulo: Editora Atlas, 2003.

M ANFRINATO, Paulino. Imposto de Importação: uma análise do lançamento e fundamentos. São Paulo: Aduaneiras, 2005. 